$4-1-2010$

\title{
Speech and Language Characteristics in Kabuki Syndrome
}

\author{
Parul Malik \\ Post Graduate Institute of Medical Education and Research \\ Anuradha Sharma \\ Post Graduate Institute of Medical Education and Research \\ Sachin Sakhuja \\ Post Graduate Institute of Medical Education and Research \\ Sanjay Munjal \\ Post Graduate Institute of Medical Education and Research \\ Naresh K. Panda \\ Post Graduate Institute of Medical Education and Research
}

Follow this and additional works at: https://nsuworks.nova.edu/ijahsp

Part of the Medicine and Health Sciences Commons

\section{Recommended Citation}

Malik P, Sharma A, Sakhuja S, Munjal S, Panda NK. Speech and Language Characteristics in Kabuki Syndrome. The Internet Journal of Allied Health Sciences and Practice. 2010 Apr 01;8(2), Article 12.

This Manuscript is brought to you for free and open access by the College of Health Care Sciences at NSUWorks. It has been accepted for inclusion in Internet Journal of Allied Health Sciences and Practice by an authorized editor of NSUWorks. For more information, please contact nsuworks@nova.edu. 


\title{
Speech and Language Characteristics in Kabuki Syndrome
}

\begin{abstract}
The aim of this study was to delineate the language difficulties in Kabuki Syndrome. At presentation, the child with Kabuki Syndrome had waddling gait, dolicocephaly, and frontal bossing. On administering an Indian standardized test (Linguistic Profile Test), different aspects of spontaneous language production were analysed. Receptive language skills were within normal limits, but expressive language skills showed deficits in semantic and syntactic areas. Articulation errors appeared mainly due to poor oral-motor coordination and hypotonia. A dull flat pattern of speech was characteristic to the child.
\end{abstract}




\title{
IJIAHISP \\ The Internet Jour mal of Allied Health Sciences and Practice \\ http://ijahsp.nova.edu
}

A Peer Reviewed Publication of the College of Allied Health \& Nursing at Nova Southeastern University

Dedicated to allied health professional practice and education

http://ijahsp.nova.edu Vol. 8 No. 2 ISSN 1540-580X

\section{Speech and Language Characteristics in Kabuki Syndrome - A Case Report}

\author{
Parul Malik ${ }^{1}$ \\ Anuradha Sharma, MASLP2 \\ Sachin Sakhuja ${ }^{3}$ \\ Sanjay Munjal, $\mathrm{PhD}^{4}$ \\ Naresh K. Panda, MBBS, MS 5
}

1. UG Student (Audiology and Speech Language Pathology, Post Graduate Institute of Medical Education and Research

2. Junior Speech Therapist, Post Graduate Institute of Medical Education and Research.

3. PG Student (Audiology and Speech Language Pathology, Post Graduate Institute of Medical Education and

Research.

4. Incharge, Speech and Hearing Unit, Post Graduate Institute of Medical Education and Research

5. Department Head, Otolaryngology Department, Post Graduate Institute of Medical Education and Research

Chandigarh, India

CITATION: Malik, P., Sharma, A., Sakhuja, S., Munjal, S., Panda, N. Measuring the Quality of Rural-Based, Government Health Care Workers in Nepal. The Internet Journal of Allied Health Sciences and Practice. April 2010. Volume 8 Number 2.

\section{ABSTRACT}

The aim of this study was to delineate the language difficulties in Kabuki Syndrome. At presentation, the child with Kabuki Syndrome had waddling gait, dolicocephaly, and frontal bossing. On administering an Indian standardized test (Linguistic Profile Test), different aspects of spontaneous language production were analysed. Receptive language skills were within normal limits, but expressive language skills showed deficits in semantic and syntactic areas. Articulation errors appeared mainly due to poor oral-motor coordination and hypotonia. A dull flat pattern of speech was characteristic to the child.

\section{INTRODUCTION}

Kabuki Syndrome (KS), also known as Kabuki Makeup Syndrome, KMS, or Niikawa Kuroki Syndrome, is a very rare paediatric congenital disorder of unknown cause with multiple congenital anomalies and mental retardation. It is named Kabuki because of the facial resemblance of the affected individuals with white kabuki makeup, a Japanese traditional theatrical form. Genetic studies reveal submicroscopic duplication on the $8^{\text {th }}$ chromosome at $8 p$ 22-23.1 to be the cause behind this disorder. Earlier it was thought that this condition was much more common in the Japanese population. However, since 1981, there have been increasing reports of KS in a wide variety of ethnic groups, including patients of Northern European, Brazilian, Philippine, Vietnamese, Arab, East Indian, Chinese, Mexican and African descent. Its frequency of occurrence is 1 in 32000 births.

\section{General Characteristics:}

Niikawa et al in 1988 described Kabuki as multiple congenital problem characterized by five cardinal manifestations: (1) A characteristic face with long palpebral fissures, large protruding ears, arched eyebrows, and a depressed nasal tip found in $100 \%$ of their patients; (2) Skeletal anomalies including brachydactyly and scoliosis in $92 \%$ of their patients; (3) dermataglyphic abnormalities including increased digital ulnar loops and persistence of fetal fingertip pads in $93 \%$ of their patients; (4) mild to 
moderate mental retardation with average IQs of 50 to 62 in $82 \%$ patients and (5) postnatal growth deficiency found in $92 \%$ of their patients. ${ }^{6}$

Some of major and minor features with their percentage of occurrence in Kabuki Syndrome are described below. ${ }^{7}$ The current data shows the variability in the expression of the symptoms in Kabuki Syndrome (See Table 1).

Table 1. Features of Kabuki Syndrome

\begin{tabular}{|l|l|}
\hline \multicolumn{1}{|c|}{ Clinical Feature } & Patient with KS (Cumulative percent) \\
\hline \multicolumn{2}{|c|}{ Major features } \\
\hline Characteristic face & 100 \\
\hline Long palpebral fissures & 99 \\
\hline Abnormal dermatoglyphics & 96 \\
\hline Short nasal septum & 92 \\
\hline Persistent fingertip pad & 89 \\
\hline Malformed ear & 87 \\
\hline Arched eyebrows & 85 \\
\hline IQ<80 & 84 \\
\hline Prominent ears & 84 \\
\hline Depressed nasal tip & 83 \\
\hline Short 5th digit & 79 \\
\hline Joint laxity & 74 \\
\hline High-arched palate & 72 \\
\hline Abnormal dentition & 68 \\
\hline Hypotonia & 68 \\
\hline Short Stature (<2 SD) & 55 \\
\hline Ptosis & 50 \\
\hline \multicolumn{2}{|c|}{ Minor features } \\
\hline Cardiovascular anomaly & 42 \\
\hline Cleft lip and/or palate & 35 \\
\hline Scoliosis & 35 \\
\hline Deformed verterbrae/rib & 32 \\
\hline Blue Sclera & 31 \\
\hline Kidney/urinary tract malformation & 28 \\
\hline Premature thelarche & 28 \\
\hline Hearing loss & 27 \\
\hline Lower lip pits & 27 \\
\hline Cryptorchidism & 24 \\
\hline Preauricular pits & 22 \\
\hline Hip dislocation & 18 \\
\hline Seizures & Percentage affected \\
\hline & $50 \%$ \\
\hline Behavioral feature & $30 \%$ \\
\hline Unusually sociable & $87 \%$ \\
\hline Engaged in minimal interaction with others & \\
\hline Liking routine & \\
\hline Having a happy disposition- & \\
\hline
\end{tabular}

\section{CLINICAL REPORT}

We describe here a 7-year-old male child who reported to the Speech and Hearing Unit, Department of Otorhinolaryngology and Head and Neck Surgery, Post Graduate Institute of Medical Education and Research, Chandigarh, India. This case leads us to explore and get an insight into the diagnostic and treatment procedure for a child with KABUKI SYNDROME. 
The child was born prematurely and developed asphyxia at birth. The child had congenital non obstructive hydrocephalous. Post natal history showed delayed developmental and social milestones. Family history was not contributory.

\section{MRI Brain}

Mild dilation of both lateral ventricles was present. Cerebral parenchyma was normal. Cerebellum and brainstem was also found to be normal. Presence of mild non-obstructive hydrocephalous was revealed.

\section{MRI Spine}

Diffuse atrophy with intramedullary T2 hyperintense signal noted in the dorsal cord extending form T3 to T11 vertebral level. Posterior wedging of D8,D9 and D10 vertebral bodies with straightening of lower dorsal spine was revealed which was suggestive of Syrinx / Diastematomyelia.

\section{General Examination}

General Examination of the child showed prominent eyes, high arched palate, dolicocephaly, and frontal blossing. He had short stature $(109 \mathrm{~cm})$ accompanied with significant midfacial hypoplasia. Maxillary recession and mid-fall hypoplasia predisposed him to the development of a small dental/arch and malocclusion. He had a waddling gait and multiple callosities in knee were found to be present. Psychological evaluation revealed that child has borderline Intelligence Quotient (IQ=71). Conditioning audiometry results indicated hearing sensitivity to be within normal limits.

\section{Speech and Language Assessment}

Informal assessment revealed that the child communicated mainly through verbal mode along with few gestures. He could follow multidirectional complex commands. The child usually communicated in phrases of greater than 3 words. He used simple sentences to communicate. He had a receptive vocabulary of 1200 to 2000 words and expressive vocabulary of 800 to 1500 words approximately, but grammatical errors still persist. Moreover, he initiated conversations or activities and exchanges information. He had no obvious fluency disorder. Few misarticulations (dentals, fricatives, and sibilants) were observed which may be attributed to dental malocclusion. Simplification of clusters was also observed. His speech was characterized by a dull flat pattern. Additionally, the prosody and articulation errors often became more pronounced as spontaneous verbal utterances increased in length and complexity, so intelligibility was negatively impacted. Abnormal oral resonance was also found owing to high arched palate and oral motor hypotonia. The child was illiterate and has not attended any formal schooling.

Linguistic Profile Test: A standardized language test for ages 3 to 7 years by the National Institute of Hearing Handicapped and Regional Rehabilitation Training Centre (RRTC) Madras, India, under UNICEF sponsored project, was administered to look into the deep insights of his language ability. Domains like Phonology, Syntax, and Semantics were assessed.

1) Phonology: the child showed good phonemic discrimination and expression. In running speech, however, the child had poor performance in analysing clusters and answering verbally.

2) Semantics: semantic discrimination was intact. Under semantic expression, the child did well with naming and lexical categories. However, his performance was poor on tasks involving synonymy, antonymy, and homonymy. He could respond to all polar questions and semantic anomaly questions precisely. Furthermore, his performance was not at par in paradigmatic and syntagmatic relations, semantic contiguity, and semantic similarity.

3) Syntax: it appeared that child had poor performance in tasks involving morphophonemic structures, tenses, PNG markers, case markers, transitives, intransitives and causatives, sentence types, predicates, conjunctions, comparatives and quotatives, conditional clauses, and participal constructions while he was a little fair with plural forms.

The Linguistic Profile test findings suggested a receptive language age of 6.9 years and an expressive language age of 5.5 years.

\section{MANAGEMENT}

The management in this case focused on the correction of the various manifestations. The primary goal of language remediation was to teach the child strategies for comprehending spoken language and producing appropriate linguistic or communicative behaviour. The parents of the child were also taught ways of encouraging and enhancing the child's communicative skills. During the sessions, communicative tempting circumstances were created. Moreover, exercises like tongue wiggling, tongue circling, oral pressure maintenance, blowing, and sucking were advised to improve the oral musculature. Tasks involving words and associating with their meaning were used for improving the domain of semantics. 
Furthermore, articulatory drills, supplemented with appropriate feedback, were used to correct the misarticulations. Cryostimulation (stimulation through ice) was done to improve the tongue compressible force and its movements. The therapy as a whole seemed to be very effective as there was a significant improvement in the articulation and the semantics domain of the child. The mean length of utterance was increased and his expressive age on the scale also showed significant improvement.

\section{DISCUSSION}

The physical characteristics of the child with Kabuki syndrome include prominent eyes, high arched palate, frontal bossing etc, are typical of a previously reported series. ${ }^{8}$ Cleft lip and cleft palate has also been described in approximately one-third of patients, while high arched palate has been reported in almost two-thirds of patients. ${ }^{9}$

Our patient had significant midfacial hypoplasia, which is in accordance with the study reported by Matsune et al., 2001, that maxillary recession and midfacial hypoplasia may predispose patients with Kabuki Syndrome to the development of small dental arch and malocclusion. ${ }^{10}$ Waddling gait and multiple callosities in the knee are commonly observed in Kabuki Syndrome. ${ }^{11-12}$

A significant delay in expressive language as revealed in our child is a commonly reported feature of Kabuki Syndrome. Upton et al reported a history of delayed speech and language acquisition in 6 individuals and were receiving speech services. ${ }^{13}$ Poor morphosyntactic, lexical, and pragmatic difficulties were observed in six Dutch speaking kabuki syndrome children. ${ }^{14}$ Similar findings were also reported by Van Lierde et al. ${ }^{15}$ The reduced precision in articulation skills can be attributed to dental malocclusion, hypotonicity, and high arched palate. ${ }^{13}$

Linguistic Profile test (Indian Standardized diagnostic tool) revealed deficits in areas of semantics and morphosyntactic abilities.

As we are aware, there is no cure for Kabuki Syndrome. Treatment of the condition is variable and focusses on correcting the different manifestations of the condition and on strategies to improve the overall functioning and quality of life of the affected individual.

\section{REFERENCES}

1. Milunsky JM, Huang JM. Unmasking Kabuki syndrome: chromosome 8p22-8p23.1 duplication revealed by comparative genomic hybridization and BAC-FISH. Clin Genet. 2003:64;509-16.

2. Braun OH, Schimd E. Kabuki makeup syndrome (Niikawa-Kuroki syndrome) in Europe. J Pediatr. 1984:105;849-50.

3. Gillis R, Klar A, Gross-Kieselstein E. The Niikawa-Kuroki (Kabuki make-up) syndrome in a Moslem Arab child. Clin Genet. 1990:38;378-81.

4. PeBenito R, Ferretti C. Kabuki makeup syndrome (Niikawa-Kuroki syndrome) in a black child. Ann Ophthalmol. 1989:21;312-5.

5. Kabuki Syndrome Network; www.kabukisyndrome.com.12 $2^{\text {th }}$ Aug 2008.

6. Niikawa N, Kuroki Y, Kajii T, et al. Kabuki make-up(Niikawa-Kuroki) syndrome:a study of 62 patients. Am J Med Genet $.1988 \mathrm{Nov}: 31(3) ; 565-89$.

7. Matsumoto N, Niikawa N. Kabuki make-up syndrome; a review. Am J Med Genet. 2003:117C;57-65.

8. Niikawa N, Matsuura N. Kabuki make-up syndrome: a syndrome of mental retardation, unusual facies, large and protruding ears, and postnatal growth deficiency. J Pediat.R. 1981:99;565-9.

9. Burke LW, Jones MC. Kabuki syndrome: Underdiagnosed recognizable pattern in cleft palate patients. Cleft Palate Craniofac J. 1995:32;77-84.

10. Matsune K, Shimizu T, Tohama T, et al. Craniofacial and dental characteristics of Kabuki Syndrome. Am J Med Genet. 2001;98:185-90.

11. Matsumoto N, Niikawa N. Kabuki make-up syndrome; a review. Am J Med Genet. 2003:117C; 57-65.

12. Ikegawa $S$, Sakaguchi $R$, Kimizuka $M$, et al. Recurrent dislocation of the patella in Kabuki make-up syndrome. $J$ Pedeatr Orthop 1993:13;265-7.

13. Upton S, Stadter CS, Landis P, Wulfsberg EA. Speech Characteristics in the Kabuki Syndrome. Am J Med Genet A. 2003:116A(4);338-41.

14. Defloor T, Van Borsel J, Schrander-Stumper CT, Curfs LM. Expressive language in children with Kabuki Syndrome. Am. J. Med Genet. A. 2005 Jan 30;132A(3);256-9.

15. Van Lierde KM, Van Borsel J, Van Cauwenberge P. Speech patterns in Kabuki make-up syndrome: A case report. Journal of Communication Disorders. 2000:33(6);447-62. 